\title{
Synthesis and Reactivity of a Pentacoordinated Thiolate-Based Imido-Alkylidene W(VI) Complexes
}

\author{
Florian Allouche, Victor Mougel, Wolfram Grüning and Christophe Copéret* \\ Department of Chemistry and Applied Biosciences, ETH Zürich, Vladimir Prelog Weg 1-5, 8093 Zürich - Switzerland \\ e-mail: ccoperet@ethz.ch \\ * Corresponding author
}

Dedicated to the memory of Yves Chauvin

\begin{abstract}
Attempt to synthesize a bis-thiolate tungsten alkylidene catalysts with bulky arenethiolates unexpectedly yielded upon activation of DME a pentacoordinated complex of general formula [W(NAr) $\left.\left(\mathrm{CHCMe}_{3}\right)\left(\mathrm{SAr}^{\prime}\right)\left(\kappa^{2}-\mathrm{O}-\mathrm{CH}_{2}-\mathrm{CH}_{2}-\mathrm{OMe}\right)\right]$, which is active towards self-metathesis of cis-4-nonene compared to the parent bis-benzenethiolate.
\end{abstract}

\begin{abstract}
Résumé - Synthèse et réactivité de complexes imido-alkylidène pentacoordinés du tungstène(VI) avec des ligands thiolates - Des essais dans le but de synthétiser un catalyseur bis-thiolate tungsten alkylidène comprenant des arènethiolates encombrés ont permis, via l'activation du DME, la synthèse inattendue d'un complexe de formule générale [W(NAr) $\left.\left(\mathrm{CHCMe}_{3}\right)\left(\mathrm{SAr}^{\prime}\right)\left(\kappa^{2}-\mathrm{O}-\mathrm{CH}_{2}-\mathrm{CH}_{2}-\mathrm{OMe}\right)\right]$, qui s'avère être active vis-à-vis de l'autométhatèse du cis-4-nonène en comparaison avec l'homologue bisbenzènethiolate.
\end{abstract}

\section{INTRODUCTION}

Alkene metathesis plays a key role in petrochemical and polymer industries $[1,2]$, and has also become widely used for organic synthesis. For these reasons, the development of homogeneous and heterogeneous metathesis catalysts still attracts major attention [3, 4]. Well-defined alkylidenes in high oxidation states, with electron-withdrawing ligands were identified as highly efficient metathesis catalysts [5-7], following the proposal by Chauvin that they were key intermediates $[8,9]$. Recent progress in the understanding of the structure-activity relationship, involving surface chemistry [10-13] combined with computational studies [14-17], has highlighted trends for a more rational design of alkene metathesis catalysts and shown in particular that dissymmetry at the metal center can bring about high activity. In particular, $\mathrm{d}^{0}$-metal alkylidene sites with two ligands of very different electron donation abilities would favor low energy barriers for coordination of the olefin while also destabilizing the metallacyclobutane intermediates, leading to overall more active catalysts [18]. MAP (MonoAlkoxide Pyrrolide) complexes illustrate perfectly this concept [2, 19-23].

Introducing a strong $\sigma$-donor ligand like thiolate [24], in combination with the weak $\sigma$-donation of surface silanolates [25], showed very good activity [26]. Here, we explore the formation of tungsten imido alkylidene systems with a bulky arenethiolate ligand. While the aim was to obtain Z-stereoselective catalysts, we show that bulky thiolate ligands lead to the unexpected formation of the pentacoordinated complex $\left[\mathrm{W}(\mathrm{NAr})\left(\mathrm{CHCMe}_{3}\right)(\mathrm{SAr})\left(\kappa^{2}-\mathrm{O}-\mathrm{CH}_{2}-\mathrm{CH}_{2}-\right.\right.$ $\mathrm{OMe}$ ) [27] (Scheme 1) and discuss its reactivity towards alkene.

Starting from commercial 2,6-dibromoaniline a Sandmeyer reaction affords 1,3-dibromo-2-iodobenzene. Adding a solution of three equivalents of $\mathrm{MesMgBr}$ in THF 

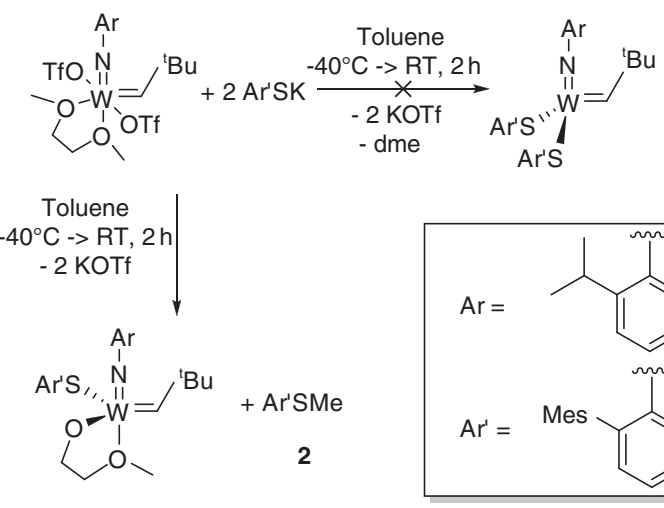

1

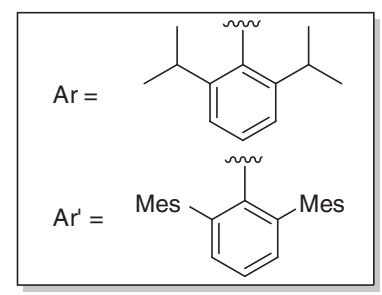

Scheme 1

Synthesis of W(NAr)(CHCMe 3$)\left(\mathrm{SAr}^{\prime}\right)\left(\kappa^{2}-\mathrm{O}-\mathrm{CH}_{2}-\mathrm{CH}_{2}-\mathrm{OMe}\right), 1$.

generates $\left(2,2^{\prime \prime}, 4,4^{\prime \prime}, 6,6^{\prime \prime}\right.$-hexamethyl-[1, $1^{\prime}: 3^{\prime}, 1^{\prime \prime}$-terphenyl]$2^{\prime}$-yl)magnesium bromide, before being first quenched with an excess of sulfur and then reduced with $\mathrm{LiAlH}_{4}$ to give the thiol with a global $44 \%$ yield. Deprotonation by $\mathrm{KH}$ give the desired potassium thiolate. The reaction of two equivalents of the large thiolate ligand KSAr' by salt metathesis synthetic route [28] with [W(NAr) $\left.\left(\mathrm{CHCMe}_{3}\right)(\mathrm{DME})(\mathrm{OTf})_{2}\right]$ lead to the clean formation of a $c a$. one-to-one mixture of [W(NAr) $\left.\left(\mathrm{CHCMe}_{3}\right)\left(\mathrm{SAr}^{\prime}\right)\left(\kappa^{2}-\mathrm{O}-\mathrm{CH}_{2}-\mathrm{CH}_{2}-\mathrm{OMe}\right)\right]$ (1) and $\mathrm{MeSAr}$ ' (2), in place of the expected dithiolate complex (Scheme 1).

The removal of one of the methyl group of the DME ligand most likely arises from the reaction of Ar'SK with the coordinated DME on the Lewis acidic W center, similarly to the demethylation of methylethers by thiolate in the presence of Lewis acids [29].

The two reaction products $\mathbf{1}$ and $\mathbf{2}$ were obtained as crystalline materials in $62 \%$ and $72 \%$ yield, respectively. They are easily separated as pure material as a result of their difference of solubility and their tendency to form crystalline materials. Both products were fully characterized by XRD, ${ }^{1} \mathrm{H}$ and ${ }^{13} \mathrm{C}$ NMR (Nuclear Magnetic Resonance) spectroscopy. The structure of $\mathbf{2}$ is given in supplementary information (The Figure S5 is in the supplementary information. CCDC 1409694 contains the supplementary crystallographic data). The single crystal XRD study of $\mathbf{1}$ reveals a pentacoordinated tungsten complex of formula $\mathrm{W}(\mathrm{NAr})\left(\mathrm{CHCMe}_{3}\right)\left(\mathrm{SAr}^{\prime}\right)\left(\kappa^{2}-\mathrm{O}-\mathrm{CH}_{2}-\mathrm{CH}_{2}-\mathrm{OMe}\right)$ (Fig. 1).

The tungsten atom lies at $0.48 \AA$ above the plane defined by $\mathrm{C}_{\text {ene }}, \mathrm{O} 1$ and $\mathrm{S}$, thus resulting in a slightly distorted Trigonal BiPyramidal (TBP) molecular geometry, where the imido ligand and the $\mathrm{O} 2-\mathrm{Me}$ group from the activated DME occupy the axial positions. The tungsten center is more sterically hindered than in $\mathrm{W}(\mathrm{NAr})\left(\mathrm{CHCMe}_{3}\right)\left(\mathrm{SAr}^{\prime}\right)_{2}$ [26], giving a slightly longer W1-S1 bond distance (2.3930(5) $\AA$

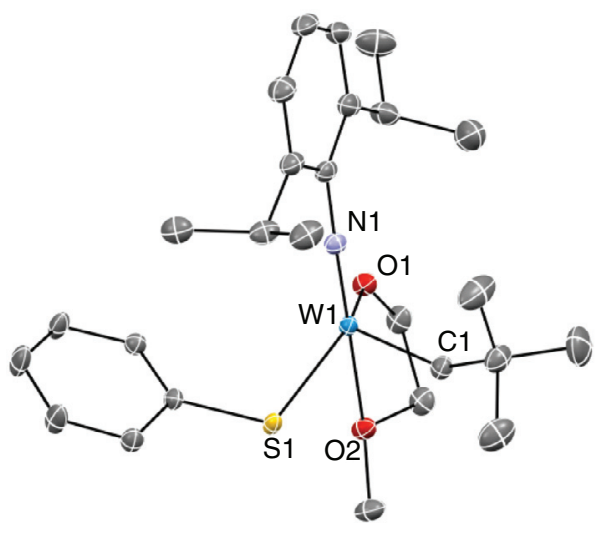

Figure 1

Thermal ellipsoid (50\% probability) of the structure of $\mathbf{1}$. Hydrogen atoms and mesityl groups on thiolate have been omitted for clarity. Selected bond distance $(\AA)$ and angles (deg): W1-N1 = 1.7486(17), W1-O1 = 1.9212(14), W1-O2 = 2.4404(15), W1-S1 = 2.3930(5), W1-C1 = 1.915(2); O1-W1$\mathrm{O} 2=68.90(6), \mathrm{O} 1-\mathrm{W} 1-\mathrm{S} 1=138.88(5), \mathrm{O} 1-\mathrm{W} 1-\mathrm{N} 1=103.18(7)$, O1-W1-C1 = 111.83(8), O2-W1-N1 = 171.80(7), O2-W1-C1 = 83.94(7), O2-W1-S1 = 81.11(4), S1-W1-N1 = 104.73(6), S1-W1-C1 = 91.43(7), C1-W1-N1 = 101.47(9).

versus $2.349(5) \AA)$. The W-N bond length (1.7486(17) $\AA$ ) is in the range of usual W-N bond, and so is the $\mathrm{W}-\mathrm{C}_{\text {ene }}$ one $(1.915(2) \AA)$. The much shorter W1-O1 bond distance (1.9212(14) $\AA$, compared to the W1-O2 at 2.4404(15) $\AA$ ), is consistent with the demethylation of DME, since the alkoxy group is a much stronger $\sigma$-donor ligand than the parent ether ligand. It is noteworthy in that such a reaction was not observed when less bulky thiolate ligands such as the 2,6-diisopropylthiophenolate or 2,4,6-triisopropylthiophenolate were used [26, 28], suggesting that the kinetics of bisthiolate complex formation is largely reduced when the steric hindrance increases, giving a notable advantage to the demethylation pathway.

The molecular complex $1(1 \mathrm{~mol} \%)$ is slightly active in the self-metathesis of cis-4-nonene to yield cis/trans-mixtures of 4-octenes, 4-nonenes and 5-decenes (The Figure S3 is in the supplementary information.) with an initial TOF of $3.10^{-3}$ $\min ^{-1}$ at $30^{\circ} \mathrm{C}$. However, the catalyst deactivates, the conversion only reaching ca. $14 \%$ after $78 \mathrm{~h}$. It is noteworthy that this catalyst is $\mathrm{Z}$-selective ( $81 \%$ after ca. $1 \%$ conversion/ 250 minutes), yielding in fine $67 \%$ Z-selectivity after $78 \mathrm{~h}$.

\section{CONCLUSION}

With the aim of synthesizing a bis-thiolate imido alkylidene tungsten complexes, the unexpected pentacoordinated 
complex W(NAr) $\left(\mathrm{CHCMe}_{3}\right)\left(\mathrm{SAr}^{\prime}\right)\left(\kappa^{2}-\mathrm{O}-\mathrm{CH}_{2}-\mathrm{CH}_{2}-\mathrm{OMe}\right)$ was obtained through the activation of DME by potassium thiolate, preventing the access of $\mathrm{W}(\mathrm{NAr})\left(\mathrm{CHCMe}_{3}\right)$ $\left(\mathrm{SAr}^{\prime}\right)_{2}$ complex so far. This pentacoordinated $\mathrm{W}$ complex is slightly active and displays a good stereoselectivity in cis-4-nonene metathesis.

\section{EXPERIMENTAL}

\section{General}

All experiments were carried out under dry and oxygen free argon atmosphere using either standard Schlenk or glovebox techniques for organometallic synthesis. For the syntheses, reactions were carried out using high vacuum lines $\left(10^{-5}\right.$ mbar) and glove-box techniques. Pentane, toluene and diethyl ether were purified using double MBraun SPS (Solvent Purification System) alumina column, and were degassed using three freeze-pump-thaw cycles before being used. DME and THF were distilled from $\mathrm{Na} /$ Benzophenone. $\mathrm{Et}_{3} \mathrm{~N}, \quad \mathrm{Me}_{3} \mathrm{SiCl}, \quad$ 2,5-dimethyl-1H-pyrrole and 2,6diisopropylamine were dried on $\mathrm{CaH}_{2}$, distilled under reduced pressure and degassed using two freeze-pump-thaw cycles. Triflic acid was purified stirring it one day over triflic anhydride, followed by distillation under reduced pressure. All InfraRed (IR) spectra were recorded using a Bruker spectrometer placed in the glovebox, equipped with $O P U S$ software. A typical experiment consisted in the measurement of transmission in 32 scans in the region from 4000 to $400 \mathrm{~cm}^{-1}$. The ${ }^{1} \mathrm{H}$ and ${ }^{13} \mathrm{C}$-NMR spectra were obtained on Bruker DRX 200, DRX 250 or DRX 500 spectrometers. The solution spectra were recorded in $\mathrm{C}_{6} \mathrm{D}_{6}$ at room temperature. The ${ }^{1} \mathrm{H}$ and ${ }^{13} \mathrm{C}$ chemical shifts are referenced relative to the residual solvent peak. W(NAr) $\left(\mathrm{CHCMe}_{3}\right)$ $(\mathrm{DME})(\mathrm{OTf})_{2}$ [28] and 1,3-dibromo-2-iodobenzene [30] were synthesized according to literature procedures.

\section{$2,2^{\prime \prime}, 4,4^{\prime \prime}, 6,6^{\prime \prime}$-Hexamethyl-[1, 1':3', $1^{\prime \prime}-$ Terphenyl]-2'- Thiol (Ar'SH)}

This synthesis was shortened compared to literature [31]. A solution of MesMgBr in THF $(32 \mathrm{~mL}, \mathrm{C}=0.978 \mathrm{M}$, $31.3 \mathrm{mmol}, 3.0$ equiv) was added dropwise over $1 \mathrm{~h}$ at RT to a solution of 1,3-dibromo-2-iodobenzene (3.638 g, $10.1 \mathrm{mmol}, 1$ equiv) in THF $(50 \mathrm{~mL})$. After $3 \mathrm{~h}$ of stirring, the solution was cooled to $-78^{\circ} \mathrm{C}$ and sulfur $\mathrm{S}_{8}(3.22 \mathrm{~g}$, $12.5 \mathrm{mmol}, 1.25$ equiv) was slowly added portionwise, resulting in an immediate colour change to deep red. The mixture was allowed to cool to RT and stirred overnight. $\mathrm{LiAlH}_{4}(3.833 \mathrm{~g}, 101 \mathrm{mmol}, 10$ equiv) was added, the reaction mixture was stirred for $8 \mathrm{~h}$, and the excess of $\mathrm{LiAlH}_{4}$ was quenched with water $(20 \mathrm{~mL})$ and $10 \%$ aqueous $\mathrm{HCl}$ solution $(60 \mathrm{~mL})$. The organic layer was separated, and the aqueous layers were extracted with $\mathrm{Et}_{2} \mathrm{O}(2 \times 60 \mathrm{~mL})$. Organic phases were dried over $\mathrm{CaCl}_{2}$ and filtered. The solvent was removed under vacuo and recrystallization at $-20^{\circ} \mathrm{C}$ in ethyl acetate finally afforded transparent needle crystals of $\mathrm{Ar}$ 'SH (1.61 g, 44\%). ${ }^{1} \mathrm{H}$ NMR (200 MHz, [ $\left.\mathrm{D}_{8}\right]$ toluene) $\delta 2.05\left(\mathrm{~s}, 12, \mathrm{Me}_{\mathrm{o}}\right), 2.36\left(\mathrm{~s}, 6, \mathrm{Me}_{\mathrm{p}}\right), 3.05(\mathrm{~s}, 1, \mathrm{SH}), 7.00$ (s, 4, $\left.\mathrm{H}_{\mathrm{m}}(\mathrm{Mes})\right), 7.06\left(\mathrm{~d},{ }^{4} \mathrm{~J}=9,2, \mathrm{H}_{\mathrm{m}}(\mathrm{Ph})\right), 7.26\left({ }^{4} \mathrm{~J}=9,1, \mathrm{H}_{\mathrm{p}}\right)$.

\section{W(NAr) $\left(\mathrm{CHCMe}_{3}\right)\left(\mathrm{SAr}^{\prime}\right)\left(\kappa^{2}-\mathrm{O}-\mathrm{CH}_{2}-\mathrm{CH}_{2}-\mathrm{OMe}\right)$}

KH (34 mg, $0.85 \mathrm{mmol}, 0.99$ equiv) was slowly added portionwise to a solution of thiol Ar'SH $(300 \mathrm{mg}, 0.86 \mathrm{mmol}$, 1 equiv) in toluene, releasing $\mathrm{H}_{2}$ during $2 \mathrm{~h}$ while a white precipitate appeared. The latter was filtrated and washed twice with cold toluene $\left(-40^{\circ} \mathrm{C}\right)$. The filtrate was concentrated and stored at $-40^{\circ} \mathrm{C}$ overnight to yield a second crop of Ar'SK which was filtrated and washed the same way, giving $311 \mathrm{mg}$ (yield: 93\%) of the potassium thiolate. Ar'SK (238 $\mathrm{mg}, 0.62 \mathrm{mmol}, 2$ equiv) was added portionwise to a cold solution $\left(-40^{\circ} \mathrm{C}\right)$ of $\mathrm{W}(\mathrm{NAr})\left(\mathrm{CHCMe}_{3}\right)(\mathrm{DME})(\mathrm{OTf})_{2}$ ( $251 \mathrm{mg}, 0.31 \mathrm{mmol}, 1$ equiv) in toluene $(10 \mathrm{~mL})$. The solution was left stirring $2 \mathrm{~h}$, resulting in a colour change to orange, accompanied by the formation of a white precipitate of KOTf. The latter was then filtrated through Celite. The solution was taken to dryness. First crystallization at $-40^{\circ} \mathrm{C}$ in pentane yielded transparent crystals of Ar'SMe $(81 \mathrm{mg}$, $72 \%$ ). After filtration, the solution was concentrated and a second crystallization in pentane at $-40^{\circ} \mathrm{C}$ afforded orange crystals of $\mathrm{W}(\mathrm{NAr})\left(\mathrm{CHCMe}_{3}\right)\left(\mathrm{SAr}^{\prime}\right)\left(\kappa^{2}-\mathrm{O}-\mathrm{CH}_{2}-\mathrm{CH}_{2}-\mathrm{OMe}\right)$ (162 mg, 62\%), which were filtrated. 'H NMR (500 MHz, $\left.\mathrm{C}_{6} \mathrm{D}_{6}\right) \delta 9.67\left(\mathrm{~s}, 1, \mathrm{CHCMe}_{3}\right), 7.11(\mathrm{~d}, 2, \mathrm{~J}=7.9), 7.04-6.99$ (m, 1), 6.97 (s, 2), 6.92 (s, 1), 6.90 (d, 2, J = 7.1), 6.86 (s, 2), 4.06 (sept, 1, J = 3.8), 3.93 (dt, 1, J = 11.5, J'= 4.3), 3.66 (sept, 2, $\mathrm{J}=6.8$ ), 3.04 (s, 3, OMe), 2.96 (sex, 1, $\mathrm{J}=4.1$ ), 2.84 (q, 1, $\mathrm{J}=4.3$ ), 2.37 (s, 6, ArMe), 2.27 (s, 6, ArMe), 2.22 (s, 6, ArMe), $1.30\left(6, \mathrm{~d}, \mathrm{~J}=6.9, \mathrm{CH}\left(\mathrm{Me}_{\mathrm{A}}\right)_{2}\right), 1.13\left(6, \mathrm{~d}, \mathrm{~J}=6.9, \mathrm{CH}\left(\mathrm{Me}_{\mathrm{B}}\right)_{2}\right)$, $1.04\left(9, \mathrm{~s}, \mathrm{CHMe}_{3}\right) ;{ }^{13} \mathrm{C}$ NMR $\delta 270.03,152.47,145.25$, $144.36,143.96,139.82,136.92,136.74,136.57,129.66$, $128.98,126.09,122.91,73.73,72.45,58.78,46.79,33.04$, 27.89, 24.26, 23.89, 21.73, 21.30, 20.93. Elemental Analysis: C $64.03 \%$ (62.18\% expected), H $7.06 \%$ (exp. $7.00 \%$ ), S 3.50\% (exp. 3.77\%), N 1.45\% (exp. 1.75\%). CCDC 1409693 contains the supplementary crystallographic data.

\section{REFERENCES}

1 Grubbs R.H. (2006) Angew. Chem. Int. Ed. 45, 3760-3765.

2 Ibrahem I., Yu M., Schrock R.R., Hoveyda A.H. (2009) J. Am. Chem. Soc. 131, 3844-3845. 
3 Ivin K., Mol H. (1997) in Olefin Metathesis and Metathesis Polymerization (2), Ivin K.J., Mol J.C. (eds), Academic Press, London.

4 Grubbs R.H. (2008) Handbook of Metathesis, Wiley-VCH Verlag $\mathrm{GmbH}$

5 Schrock R.R., Hoveyda A.H. (2003) Angew. Chem. Int. Ed. 42, 4555-4555.

6 Hoveyda A.H., Malcolmson S.J., Meek S.J., Zhugralin A.R. (2010) Angew. Chem. Int. Ed. 49, 34-44.

7 Kress S., Blechert S. (2012) Chem. Soc. Rev. 41, 4389-4408.

8 Herisson J.L., Chauvin Y. (1971) Makromol. Chem. 141, 161-165.

9 Chauvin Y. (2006) Angew. Chem. Int. Ed. 45, 3740-3747.

10 Chabanas M., Baudouin A., Copéret C., Basset J.-M. (2001) J. Am. Chem. Soc. 123, 2062-2063.

11 Blanc F., Copéret C., Thivolle-Cazat J., Basset J.-M., Lesage A., Emsley L., Sinha A., Schrock R.R. (2006) Angew. Chem. Int. Ed. 45, 1216-1220.

12 Rhers B., Quadrelli E.A., Baudouin A., Taoufik M., Copéret C., Lefebvre F., Basset J.-M., Fenet B., Sinha A., Schrock R.R. (2006) J. Organomet. Chem. 691, 5448-5455.

13 Blanc F., Berthoud R., Salameh A., Basset J.-M., Copéret C., Singh R., Schrock R.R. (2007) J. Am. Chem. Soc. 129, 8434-8435.

14 Solans-Monfort X., Clot E., Copéret C., Eisenstein O. (2005) J. Am. Chem. Soc. 127, 14015-14025.

15 Poater A., Solans-Monfort X., Clot E., Copéret C., Eisenstein O. (2007) J. Am. Chem. Soc. 129, 8207-8216.

16 Solans-Monfort X., Copéret C., Eisenstein O. (2010) J. Am. Chem. Soc. 132, 7750-7757.

17 Solans-Monfort X., Copéret C., Eisenstein O. (2012) Organometallics 31, 6812-6822.

18 Chabanas M., Copéret C., Basset J.-M. (2003) Chem. Eur. J. 9, 971-975.
19 Hoveyda A.H., Zhugralin A.R. (2007) Nature 450, 243-251.

20 Malcolmson S.J., Meek S.J., Sattely E.S., Schrock R.R., Hoveyda A.H. (2008) Nature 456, 933-937.

21 Marinescu S.C., Levine D.S., Zhao Y., Schrock R.R., Hoveyda A.H. (2011) J. Am. Chem. Soc. 133, 11512-11514.

22 Reithofer M.R., Dobereiner G.E., Schrock R.R., Müller P. (2013) Organometallics 32, 2489-2492.

23 Gerber L.C.H., Schrock R.R., Müller P. (2013) Organometallics 32, 2373-2378.

24 Jakusch T., Buglyo P., Tomaz A.I., Pessoa J.C., Kiss T. (2002) Inorg. Chim. Acta 339, 119-128.

25 Mougel V., Copéret C. (2014) Chem. Sci. 5, 2475-2481.

26 Allouche F., Mougel V., Copéret C. (2015) Asian J. Org. Chem. 4, 528-532.

27 Couturier J.L., Paillet C., Leconte M., Basset J.-M., Weiss K. (1992) Angew. Chem. Int. Ed. 31, 628-631.

28 Schrock R.R., Depue R.T., Feldman J., Yap K.B., Yang D.C., Davis W.M., Park L., Dimare M., Schofield M., Anhaus J., Walborsky E., Evitt E., Kruger C., Betz P. (1990) Organometallics 9, 2262-2275.

29 Weissman S.A., Zewge D. (2005) Tetrahedron 61, 7833-7863.

30 Du C.J.F., Hart H., Ng K.K.D. (1986) J. Org. Chem. 51, 3162-3165.

31 Ellison J.J., Ruhlandt-Senge K., Power P.P. (1994) Angew. Chem. 106, 1248-1250.

Manuscript submitted in July 2015 Manuscript accepted in September 2015

Published online in March 2016

Cite this article as: F. Allouche, V. Mougel, W. Grüning and C. Copéret (2016). Synthesis and Reactivity of a Pentacoordinated Thiolate-Based Imido-Alkylidene W(VI) Complexes, Oil Gas Sci. Technol 71, 22. 